\title{
A Reading of Donald Hall's "Kicking the Leaves" · Gregory Orr
}

WHEN WILLIAM CARLOS WILLIAMS, in "A Sort of Song," calls on metaphor to "reconcile / the people and the stones," he clearly means by stones the world we inhabit, the world we move through. In that same lyric, Williams proposes a vegetative metaphor for the self, for his self: "Saxifrage is my flower that splits / the rocks." The vitality, almost stubborn muscularity of the metaphor is unmistakable and characteristic. Donald Hall's ambition in his major poem, "Kicking the Leaves," is also expressed through a metaphor from the vegetative world, but Hall's poem aims to reconcile us not to life (Williams' goal) but to death: lives are leaves.

"Kicking the Leaves" is a poem of family - four generations of Hall's personal family inhabit its seven sections. But it also belongs to the family of poems. At the source of the poem's unspoken genealogy, its genealogy of imagination, is Homer's famous metaphor from The Iliad, where Glaucos, challenged to identify himself by Diomedes, responds:

Magnanimous Diomedes, why do you ask who I am? The frail generations of men have scarcely more lineage than leaves. Wind blows them to earth in the fall, but spring brings the blossoms again. So one generation succeeds another.

A second sponsor of the leaf metaphor is Hopkins "Spring and Fall," whose "Leaves like the things of man" is the central imaginative premise for a poem of great elegiac beauty enacted as a child's dawning awareness of the mortality she shares with the world of created beings. But Hopkins' poem, unlike the passage from Homer, is also about human connectedness and awareness of others. For me, the pivotal line in the poem is "And yet you will weep and know why," where the young girl's emotional simplicity breaks through the speaker's self-satisfied philosophizing and demands a more authentic response, one that acknowledges and incorporates the deepest sources of her grief. Hall's poem shares with Hopkins' this awareness of other selves. 
Leaves. Their very multiplicity, their "droveness," seems to resist transformation into a symbol for the human condition. As if we were accustomed to the lyric symbol which thrives on the precise outline of a single, centered thing - a nightingale, say. It is their resistance, their multiplicity that is a form of the poem's generosity. Though the poem's sections tell the story of the generations of Hall's family and of his own life in time from boyhood to age, there is in the image of the multiplicity of leaves a clear sense that Hall is saying: I am only one leaf among all the leaves of human stories. We are half a step from Whitman's central invitation: "what I assume you shall assume, / For every atom belonging to me as good belongs to you."

Hall's generosity, his overcoming of the egocentrism that overwhelms so many lyric enterprises, is not his only accomplishment. As deep as that is his ability to hold the poem together so that it doesn't disperse into drifts and scuds. He does this by staying close to human story - to located anecdote. The poem is anchored in story and anecdote, yet opens up again and again toward mystery, toward the ultimate human mysteries of time and death.

It's not exactly news that the central impulse in Donald Hall's work is elegiac - that he is obsessed with elegy as others are said to be obsessed with sex or death. But it is worth noting that "Kicking the Leaves" is the triumphant culmination of this obsession. All his earlier, scattered elegiac occasions are, like raked leaves, gathered in one place: the beloved maternal grandparents and their farm, the father's early death that terrifies the son as predictive of his own, the ambivalent sense of his children's vitality and futurity, and there at the center the self longing to elegize its own perishing and be lifted up into elegy as certain saints were taken up bodily into heaven at the point of death.

The poem opens with the long, accumulating, Whitmanic lines that will characterize it as a whole. The first sentence is seven lines long; the second sentence comprises the remaining ten lines of the section.

The initial verb, "kicking," is repeated four times in section one, becoming at the outset the incantatory gesture that initiates the poem's discoveries. The first occasion of kicking the leaves locates the speaker in a moment and place (October, Ann Arbor). The second "kick" leads to an 
awareness of particular leaves (maple, poplar, elm) and a tentative metaphorical listing. With the third repetition, the poem enacts its central process - the rising up of lost or buried memories and experiences by way of an unconsciously repeated gesture - the emergence of the "involuntary memory" Proust asserted as being central to urgent art. The sound of kicking the leaves triggers associated memories that transport us into three places in Hall's past: walking to school as a boy in Connecticut, roadside New Hampshire, and finally Massachusetts in 1955. We are always located geographically in section one, and these four places are and will remain the poem's cardinal points.

We could say the language unfolds under the momentum of the sound and gesture of the repeated "kick," until each sentence arrives at the poem's obsessive center: death. The listing of specific leaves and their metaphors gets no further than three, stops (as does the sentence) at the elm's, whose fatal blight occasions the metaphor. Likewise the second sentence, with its unfolding memories, also ends with the awareness of the father's impending death.

How the poem accumulates and accretes by its dependent clauses - "from the game, in Ann Arbor, / on a day the color of soot, rain in the air ..." If this was sculpture, Hall's style would be that of a modeler, not a carver; rather than stripping away toward a lyric center, he slaps on phrase after phrase like lumps of clay, building his shape gradually. Each phrase adding, modifying, locating - always locating and making local. How powerfully that strategy is at work in the opening of section two:

Each fall in New Hampshire, on the farm where my mother grew up, a girl in the country

Section two is structured around two anecdotes. The general ("Each fall . . .") sequeing into the particular ("One November . . ."), even as the grandson replaces his mother and thus preserves the basic family unit with the grandparents. People at work, moving around each other at their tasks - achieving an intimacy and harmony based on proximity and shared labor:

three of us sitting together, silent, in gray November. 
And always the clauses and phrases - clustering, accumulating, layering like leaves, modifying - here undercutting, there aggrandizing-always going on and on - a poem built on commas.

In section two the leaves are a minor, naturalistic part of the farm's dynamic life. They have a function - to insulate the house in winter, preserve its heat. In this section the reader becomes aware of how much of the poem relies on the power of descriptive language.

Section three presents another triadic anecdote, again particularized by its prepositional phrases: "One Saturday when I was little, before the war ..." The whole anecdote/section is a single sentence, revealing the unity of the poem's stylistic and thematic strategy: to bind together in a single unit of speech the disparate figures and facts - a wholeness out of the bits of bright fact and memory, the scattered remnants of mortality-leaves gathered up into the single pile of the sentence.

The anecdote of this triad (father, son, mother) is of an interactive intimacy, not just the silent parallel labor of section two. The father plays with the son, makes contact with him; the mother "sees" them and responds with both pleasure and concern. Since this is elegy, concern has the final word: ". . . afraid I would fall and be hurt."

Section four returns to the opening scene of section one, echoing the opening phrase: "Kicking the leaves today, as we walk home together." Now the poem's guiding, overarching metaphor begins to assert itself: the connections between the human world and the world of leaves. The stepping stone to this is the football pennants "as many and bright as leaves." From there to the third triadic arrangement of people: father (speaker), daughter, and son. People are like trees: the daughter like a birch; the son, a maple. Again, we have the triad of a basic family unity, but here the speaker, for all his joy and pride in his children (expressed in the flattery of the similes), is about to become the locus of loss. The triad is not that of the child (speaker) and two parents (section three) or the youth (speaker) and his grandparents (section two), where the focus was on the child. Here it is the speaker as parent and his two children, and their futurity points away from him as the point of origin. It is an "unstable" triangle, a triad of imminent loss.

Sentence one ( $91 / 2$ lines) culminates in the grown son's eagerness to de- 
part the family. Sentence 2 (the next 9 lines, the rest of the section) focuses on the father ("I") as he experiences the vertigo of loss. Standing by a totem pile of leaves, he watches their departure ("their shapes grow small with distance") and recognizes in it his own diminishment and mortality. In an early, grimly elegant and witty poem, "My Son, My Executioner," the "birth" of one generation was seen as representing the death of the other, parental generation and gave a sinister, darkly Freudian undertone to Hall's elegiac impulse. But here, in "Kicking the Leaves," we are outside in the sun and fresh air of autumn, not trapped in the claustrophobic lucubrations of the self alone with its thoughts in a closed house. Here, the intimations of mortality are seen and accepted: "as I go first / into the leaves, taking / the step they will follow ..."

At first, "into the leaves" seems a euphemism for "into the ground," "into the grave," but it is one of the poem's burdens and triumphs to make the descent into the leaves as believable an imaginative possibility as it was when first presented to us in section three as the naturalistic possibilty of a kid tumbling in leaves with his father. By section six, the leaves will become the entrance to the underworld of the dead. And by section seven, they will have expanded to become not just a pile of leaves, but an entire ocean - an elemental, the elemental entity and emblem for the human condition of mortality; as all pervasive and insisted upon as Whitman's grass in his great celebratory elegy, "Song of Myself."

The opening line of section five picks up and transforms the last line/gesture of section one; here, instead of the father's death, we have the "birth" of poems, the "rebirth" of poems and creativity.

Sections five and six break the pattern of the long opening sentence-in fact, the first lines of both sections are end-stopped sentences.

For the first time, the poem shifts away from family memory and family event by introducing the theme of poetry: "This year the poems came back, when the leaves fell." One purpose of elegy is to articulate a loss and then locate a consolation for that loss. Although "Kicking the Leaves" has extended its elegiac ambition widely (and will, by poem's end, extend it even further), the end of section four has temporarily focused the imminent loss in the person of the speaker himself-it is he who will "go first / into the leaves." From this loss that is one's own death emerges the consolation that has always created and defined the personal poet: poems. 
Only at the very moment that this consolation asserts itself most strongly ("I looked up into the maples / and found them, the vowels of bright desire ...") can the speaker acknowledge the horror of the years without poems. The image for this horror, a ghoulish mynah bird/ rooster, is ironically located - up among the trees whose leaves are associated with poems, but the branches are bare and such a sinister bird seems equally at home in the deathful confinement of chicken wire and cinderblock, is in fact at home everywhere, haunting and taunting the speaker with its "red eye with no lid."

If there was any question that the poet's companion bird was an image of life without poems (which is also, the poem would have it, death-inlife), then this is resolved when the word "lid" is repeated three lines after its first appearance with the bird, only now, in the opening lines of section six, it is the lid of a grave.

The red eye is now lidded, but the lids are of graves and the poem, while returning to the family (this time the paternal lineage) will impinge more fatefully than ever on the speaker. Section six seems to assert in an understated way a theory of generational diminishment (grandfather dies at 77 , father at 52) and a geographical diminishment as well (from farm to suburbs). These twin diminishments haunt the poet: Johnson's Pond has "surrendered to houses" and the speaker is now intensely aware of approaching the age at which his father died. Numerological doom presides over this section even as the ecstasy of nostalgic intimacy erupts through the middle:

leaves in the air Oh, how we flung! How they tumbled and fluttered around us,

like slowly cascading water, when we walked together..."

The final section takes its cue from the ecstatic verbs of section six, not its gloomy numbers. The wisdom of verbs espoused here is reminiscent of that in Galway Kinnell's "Another Night in the Ruins"-if we are to be consumed by the fire, we should embrace it and become the fire. But Kinnell's poem, despite its overt rejection of the phoenix as emblem of the self, still believes in a transformative event at the moment of death - the transcendent ascent of annihilation implicit in his governing image of fire. Hall's poem re- 
fuses transformation, stays in the human shape, and asserts a descent. The three verbs in the opening line propound a metaphysics of passionate defeat in which gravity (and death) get two verbs and the human will gets one:

"Now I fall, now I leap and fall ..."

Or we could understand the phrasing as being a statement ("Now I fall") which the poet corrects even as he says it in order to express that his death is not a fate but a willed act: "now I leap and fall."

And the motive for such a gesture is revealed as intensified life: "to feel ... to feel."

Now the leaves are everything. Now the leaves that represent the mortal condition are omnipresent - they are night and ocean - a cosmic, solemn, ecstatic vastness into which the individual self is absorbed. We have entered Whitman's imaginative territory here - the shadow Whitman of rapturous elegies whose "Out of the Cradle Endlessly Rocking" finds the sweetest word, the most "delicious" world of all, to be what the waves whisper: "death, death, death, death ..."

As with Whitman's poem, there is a sense of death as a being taken back - Hall experiences the death as an ecstatic regression - "the soft laps of leaves." And in fact, as he swims down to the bottom of the leafpile he discovers his grandparents' farmhouse. Its enclosed intimacy has become all things: womb, tomb, beloved farmhouse of childhood. In a series of essays called Seasons at Eagle Pond (Ticknor and Fields, 1987), Hall writes of the joy of New England winters for those who are "darkness-lovers," those who are "partly tuber, partly bear" (Hall has an early poem called "Selfportrait, As a Bear"); and both ingredients of the farmhouse soup, carrots and onions, mature in the earth. Here dormancy and hibernation and cozy security fuse with nostalgia, and we see that the poem has adopted a strategy Freud recommends and which Hall frequently quotes: regression in the service of the ego. Roethke did the same thing throughout his "Lost Son" sequence-elevated regression to a spiritual and poetic principle.

Another Whitman poem, section 6 of "Song of Myself," is worth mentioning in connection with this culminating event of Hall's poem. Significantly, it is the section where Whitman first introduces the image of grass as a vehicle for his obsessive concerns, as that thing in the material world that will stand for so much in his metaphysical and imaginative world. It opens 
"A child said, 'What is the grass?' fetching it to me with full hands." No sooner does Whitman express his inability to answer the mystery of the question with descriptive language, than he begins to "guess" what it is with a series of stunning and free-ranging metaphors: a flag, perfumed handkerchief, child, universal hieroglyph. Free-ranging up to a point; for when he arrives at a certain image ("And now it seems to me the beautiful uncut hair of graves"), he has encountered an obsessive theme. From that point on, Whitman's imagination circles around one of his favorite subjects: a sensual death. Whitman has entered a spiral of obsession - his imagination is no longer free and centrifugal and, for the next twenty-six lines, he circlingly descends toward his still point of obsession and the poem's final line: "And to die is different from what any one supposed, and luckier."

Hall, too, in the final section of "Kicking the Leaves," has entered the spiral of obsession; he, too, is drawn down as if in a whirlpool - "Swooping in long glides to the bottom."

Leaves are Hall's sea, not grass as in Whitman. There is no implied rebirth here, no hint of reincarnation no matter how diffuse, no "if you want me again look for me under your boot-soles." In Hall, the image of leaves, like Hopkins' Goldengrove that "leafmeal lies," cannot be imagined as leading beyond death. Presumably, Hopkins' Christianity tells him that death is not the end, that the soul rises afterward. Hall has no such faith, and for him the final ecstatic celebration of leaves and death is inextricably bound up with the consoling regressive fantasy of the farmhouse at the very bottom of the whirlpool's funnel-a personal and particular focus of intimacy. The image of this whirlpool spiral is important -it indicates that death is not a scattering of the objects and meanings of life, but a centripetal funneling, an ingathering of them.

Hall's poem accepts but transforms Homer's great metaphor. The generations of men are as leaves. But one can give assent - can leap as well as fall. The heroic acceptance of destiny. One could even argue that the Homeric consolation of leaving a name in the tribal epic through heroic behavior is also a consolation Hall's poem seeks: "the pleasure, the only long pleasure, of taking a place / in the story of leaves." But it would be important to stress the central feel of Hall's poem: not of Homer's heroic warriors, but of family intimacy and connection; a constant linking across generations, as families can do, as leaves and warriors cannot. 